\title{
Large-area fluidic assembly of single- walled carbon nanotubes through dip-coating and directional evaporation
}

\author{
Pilnam Kim ${ }^{1 *}$ and Tae June Kang ${ }^{2}$
}

\begin{abstract}
We present a simple and scalable fluidic-assembly approach, in which bundles of single-walled carbon nanotubes (SWCNTs) are selectively aligned and deposited by directionally controlled dip-coating and solvent evaporation processes. The patterned surface with alternating regions of hydrophobic polydimethyl siloxane (PDMS) (height $\sim 100 \mathrm{~nm})$ strips and hydrophilic $\mathrm{SiO}_{2}$ substrate was withdrawn vertically at a constant speed $(\sim 3 \mathrm{~mm} / \mathrm{min})$ from a solution bath containing SWCNTs $(\sim 0.1 \mathrm{mg} / \mathrm{ml})$, allowing for directional evaporation and subsequent selective deposition of nanotube bundles along the edges of horizontally aligned PDMS strips. In addition, the fluidic assembly was applied to fabricate a field effect transistor (FET) with highly oriented SWCNTs, which demonstrate significantly higher current density as well as high turn-off ratio (T/O ratio 100) as compared to that with randomly distributed carbon nanotube bundles (T/O ratio $\sim<10$ ).
\end{abstract}

Keywords: SWCNT (single-walled carbon nanotubes), Fluidic-assisted assembly, FET (field effect transistor)

\section{Background}

Controlled positioning of nanomaterials (e.g., nanotubes, nanowires, and nanoparticles) is an essential process for advances in nanoelectrical devices and photonic system [1-4]. In particular, selective and addressable deposition of SWCNTs is important for high-performance CNT based-electronic devices such as light-emitting diode, flexible display, conductive film, and transistor [5-10]. Therefore, extensive efforts have been made towards integration of individual SWCNTs into microscale devices with particular emphasis on efficiency and scalability. Several methods have been proposed to align SWCNTs, networks, or films using various principles including solution/flow based patterning [11-15], and patterned catalytic growth $[16,17]$. There still remain, however, substantial challenges that need to be overcome in order to achieve a large-area assembly in a simple, cost-effective, and reproducible manner.

\footnotetext{
*Correspondence: pkim@kaist.ac.kr

${ }^{1}$ Department of Bio and Brain Engineering, KAIST, Daejeon 34141, South Korea

Full list of author information is available at the end of the article
}

A typical bottom-up approach can be found in chemical vapor deposition (CVD) process, in which CNTs are grown on specific locations with the aid of local heating or catalytic activation $[18,19]$. Although the CVD process allows for a precise assembly of nanomaterials for CNT-based electronic or flexible devices in a geometry-controllable fashion, such bottom-up approach is inherently facing challenges such as low density, high thermal budget, and high costs. Alternatively, a solutionbased top-down approach has been introduced for scalable SWCNTs-based integrated device, which exploits site-selective attachment of SWCNTs onto patterned self-assembled monolayers (SAMs) formed via microcontact printing or dip-pen nanolithography [20-23]. The technique offers a high-throughput, low-expertise route to assembling SWCNTs without an external stimulus (e.g., electric field or local heating). Nonetheless, it is difficult or slow to attain uniform SAM patterns at nanoscale resolution that are needed for large-scale integration and precise positioning. It is also problematic that the SAM patterns are prone to contamination or undesirable chemical reaction during solution-phase coating process. Moreover, the nanotubes are usually 
covalently-functionalized with chemical groups to interact with a predefined SAM pattern $[1,24]$. In this case, the functionalized nanotubes located at defect sites have limited utility for electrical applications such as transistor and semiconducting device, since the nanotubes may not preserve the $\mathrm{sp}^{2}$ carbon structure and thus their electronic characteristics $[25,26]$.

In this work, we demonstrate a simple fluidic-assembly method for highly oriented SWCNTs patterns, using a dipcoating process onto a topographically heterogeneous interface of alternating non-polar (hydrophobic) PDMS strips on the polar (hydrophilic) $\mathrm{SiO}_{2}$ substrate. Well-defined PDMS nano-strips were created by solvent-assisted decal transfer lithography (sa-DTL) by utilizing irreversible bonding and anisotropic swelling [27]. The transferred PDMS skin layer acts as a non-wetting region against non-specific deposition of SWCNTs and induces a spontaneous, large-area assembly after selective wetting and drying. One important aspect of the current strategy, as compared to previous chemical patterning methods [28], is the use of a hydrophobic, uniformly defined physical structure ( 100 nm height) instead of chemically patterned monolayer or multilayer of SAMs. Such physically defined patterns exhibit chemical and mechanical stability for a long time. Another key aspect is the introduction of a dip-coating process as a scalable and reproducible deposition method. Unlike previous deposition processes such as direct dipping and spin coating, the dip-coating process allows us to achieve precise and selective integration of highly aligned SWCNTs onto hydrophilic locations of a topographically modified surface. As described shortly, the positioning process was widthdependent, such that the alignment accuracy was increased with decreasing the pattern width below $\sim 1 \mu \mathrm{m}$. We further demonstrate that the aligned arrays of SWCNTs can be used for a high-performance SWCNTs-FET device with high current density and turn-off ratio.

\section{Experimental section Preparation of PDMS stamps}

PDMS stamps were prepared by replica molding from silicon masters that had been prepared by photolithography. A mixture of base and curing agent $(10: 1 \mathrm{w} / \mathrm{w})$ of Sylgard 184 silicone elastomer was poured onto the patterned masters and cured at $70{ }^{\circ} \mathrm{C}$ for $2 \mathrm{~h}$.

\section{Solvent-assisted decal transfer lithography (sa-DTL)}

First, both PDMS stamp and substrate were treated by short $\mathrm{O}_{2}$ plasma treatment $(200 \mathrm{mTorr}, 60 \mathrm{~W}, 20 \mathrm{~s}$ ) for irreversible bonding. Immediately after the plasma treatment, the PDMS stamp was carefully placed on the substrate. The assembly was subsequently immersed in polar solvents such as THF or 1,2-dichlorobenzene (1.2-DCB) for $1 \mathrm{~min}$.

\section{Preparation of SWCNTs colloidal solution}

In order to obtain uniform SWCNTs, it is necessary to prepare a well dispersed colloidal solution. We conducted the following treatment for purification and dispersion. SWCNTs (ASP-100F produced by Il-jin Nanotech, Korea) were stirred in nitric acid solution at $50{ }^{\circ} \mathrm{C}$ for $30 \mathrm{~min}$ to purify and simultaneously exfoliate from bundles. Then SWCNTs were neutralized with deionized (DI) water and trapped on a membrane filter (Millipore, $0.2 \mu \mathrm{m}$ pore size, $47 \mathrm{~mm}$ diameter) using vacuum filtration. The SWCNTs on the filter were dried in a vacuum oven chamber at $80^{\circ} \mathrm{C}$ for $48 \mathrm{~h}$. We used 1,2-dichlorobenzene (1,2-DCB) as a solvent which is one of the well-known mediums appropriate for dissolution of SWCNTs 34-35 with the concentration of $0.1 \mathrm{mg} / \mathrm{ml}$. Finally, an ultrasonication process was performed for $20 \mathrm{~h}$.

\section{Dip-coating process}

Dip coating was performed by using a custom-built dip coater with controllable withdrawal velocity. The step motor was mounted on the dip coater to allow movement of the platform upward or downward with a controlled speed, and the manipulator controlled the position of the substrate. The PDMS patterned substrate was held on the hanger by a holder and the beaker filled with SWCNTs colloidal solution was set on the platform. The substrate was immersed into the prepared SWCNTs colloidal solution with the concentration of $0.1 \mathrm{mg} / \mathrm{ml}$, and slowly pulled out at the constant withdrawal velocity of $3 \mathrm{~mm} /$ min.

\section{Device fabrication and characterization}

To evaluate electrical characteristics of fluidic assembled SWCNTs, we fabricated a field effect transistor with two Au electrodes (source/drain) and a back-gate. A conventional lift-off process was used to form the electrodes on the gate-oxide. A highly conductive $4 \mathrm{in}$. P-type silicon substrate (100) resistivity: $3-6 \Omega \mathrm{cm}$ was used as the back-gate with a gate-oxide thickness of $10 \mathrm{~nm}$. The channel length (Lc) between the electrodes was varied from 2 to $20 \mu \mathrm{m}$ with an interval of $2 \mu \mathrm{m}$ (ten different spacing in total). I-V characteristics and gating effects of the devices were measured using Agilent $4156 \mathrm{C}$ parameter analyzer.

\section{Scanning electron microscopy (SEM)}

Images were taken using high-resolution SEM (S4800, Hitachi, Japan) at an acceleration voltage higher than $5 \mathrm{kV}$.

\section{Atomic force microscopy (AFM)}

AFM measurements were performed using a commercial AFM (NanoScope IV MultiMode AFM, Veeco Metrology 
LLC, Santa Barbara, CA). The scan rate was $0.5 \mathrm{~Hz}$ and 256 lines were scanned per sample. Tapping mode tips, OMCL_AC240TM-B2 with spring constant $0.9-2.2 \mathrm{mN}$, were obtained from OLYOMPUS (Japan). Data were processed using Nanoscope III 4.31r6 software (Veeco Instruments Inc.)

\section{Results and discussion}

Formation of stripe-patterned substrate and aligned bundles of SWCNTs

Figure 1a illustrates the process to create well-defined nano-stripes formed by sa-DTL. Briefly, the sa-DTL process utilizes a swelling-induced stress gradient due

\section{a Solvent assisted Decal Transfer Lithography (sa-DTL)}
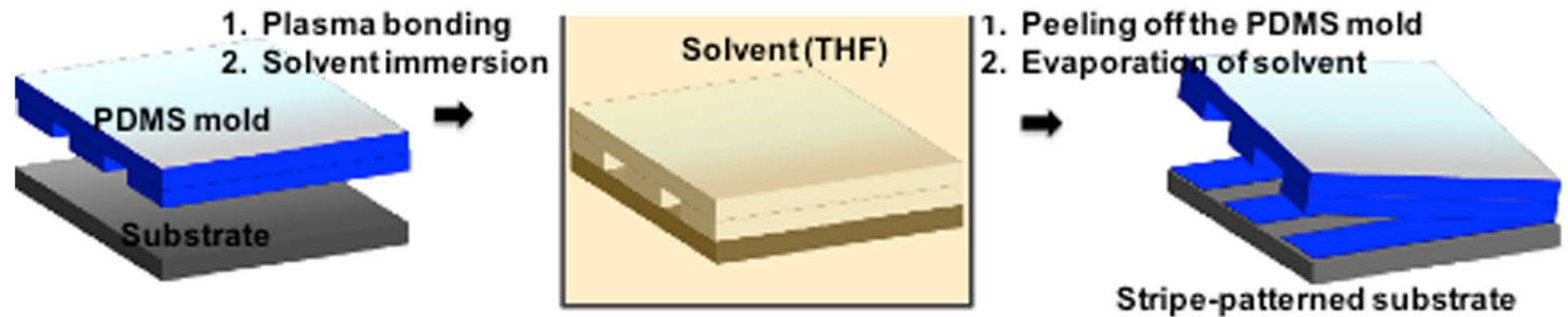

b Dip-coating process with stripe-patterned substrate

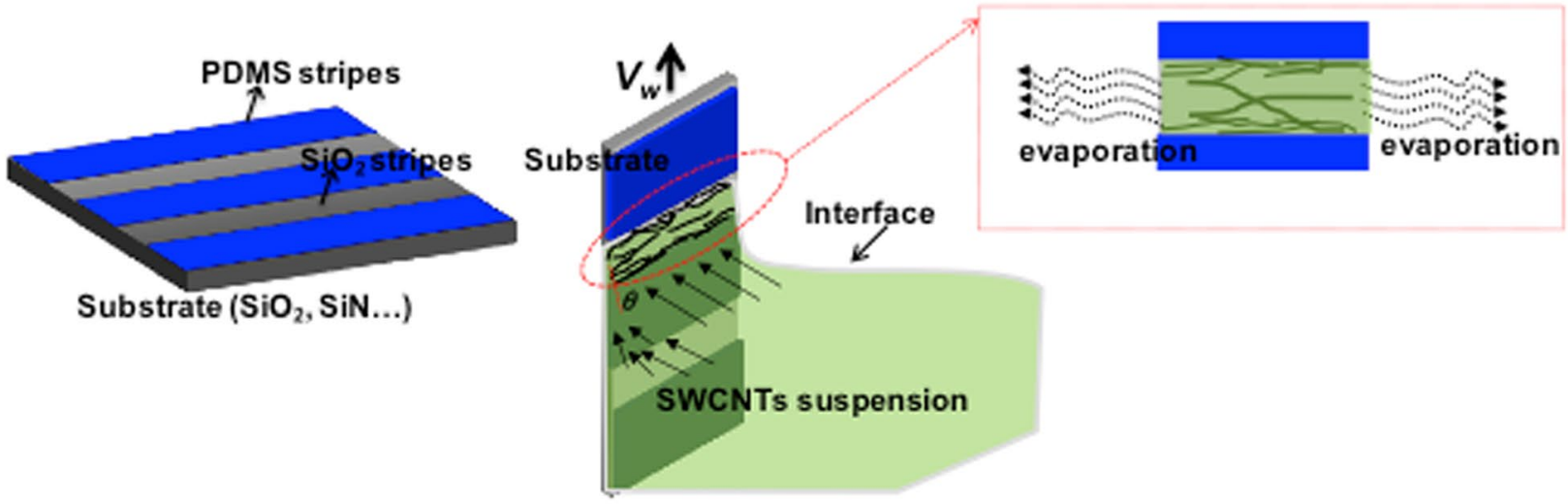

c Fabrication results of (i) PDMS skin layer and (ii) aligned SWCNTs bundles
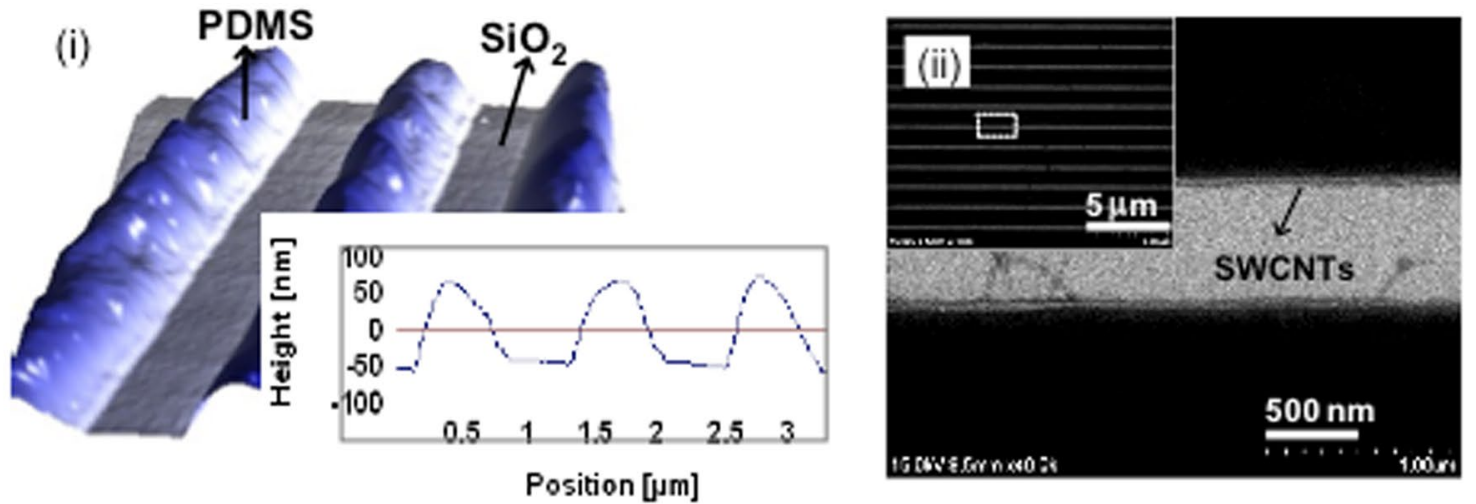

Fig. 1 a Schematic illustration of the procedure to fabricate patterned PDMS strips by solvent-assisted decal transfer lithography (sa-DTL). b Dipcoating process with strip-patterned substrate. c Fabrication results of transferred PDMS layer $(\sim 100 \mathrm{~nm})$ and aligned bundles of SWCNTs: (i) AFM image of transferred PDMS pattern on $\mathrm{SiO}_{2}$ substrate with the inset showing cross-sectional line profile. The height of patterned PDMS is $\sim 100 \mathrm{~nm}$. (ii) SEM image showing SWCNTs alignment onto strip-patterned substrate by dip-coating process 
to anisotropic swelling of PDMS that is immersed in an organic solvent such as tetrahydrofuran (THF). The transferred PDMS skin preserves the original hydrophobic nature of PDMS (static contact angle $\sim 113^{\circ}$ ) [27] and thus can act as a patterned resist for selective wetting and deposition of SWCNTs. After preparing the PDMS nano-strips, a dip-coating was performed with a custombuilt dip coater (Fig. 1b). The patterned surface contains non-polar strips (PDMS region) on the polar substrate $\left(\mathrm{SiO}_{2}\right.$ region$)$, which provides selective wetting and drying when the surface is withdrawn at a constant velocity $\left(V_{w}\right)$ of $3 \mathrm{~mm} / \mathrm{min}$ from the bath containing well-dispersed SWCNTs solution. It is noted that the strips were oriented parallel to the liquid interface for better alignment along the strip direction as shown in Fig. 1b. When the strips were oriented vertical to the surface, a similar directional drying was observed at the edges, together with continuous thinning of liquid layers along the pulling direction, resulting in non-uniform distribution of nanotube bundles or the formation of discrete liquid droplets by Rayleigh instability $[29,30]$. As shown in the AFM image of Fig. 1c, the transferred PDMS layer shows good pattern fidelity and structural integrity, with a pattern height of $\sim 100 \mathrm{~nm}$ (i). Also, the SEM image indicates that the SWCNTs bundles are well aligned along the strip edges over a large area (ii).

In the dip-coating process presented here, the polarity difference between PDMS and $\mathrm{SiO}_{2}$ regions can induce selective localization of SWCNTs along the strip direction. Specifically, when such a surface is drawn vertically from the SWCNTs solution, a thin meniscus is formed selectively on the hydrophilic $\mathrm{SiO}_{2}$ substrate at the three phase contact line (solid-liquid-vapor interface) with a contact angle $\theta$ (Fig. 1b). As the pulling velocity is sufficiently slow, the solvent starts to evaporate mostly from the pattern edges, leading to convective transport of the SWCNTs that is similar to the well-known coffee-ring flow [31]. In addition, the confined geometry of a topographically patterned surface strongly influences the direction of evaporation, so that the liquid layer dries and forms aligned bundles of SWCNTs along the nano-strips [32]. This directional evaporation significantly enhances align accuracy and pattern fidelity as compared to other solution-based methods (e.g., spin-coating, dipping). Recently, this edge pinning and drying has been successfully applied to align carbon nanotubes films [32] and assemble nanoparticles on pre-patterned surfaces [33].

\section{Construction of phase map on the alignment morphology}

In the experiment, we observed different alignment morphology with different width of nano-stripes. As shown in Fig. 2, various widths $\left(\mathrm{W}_{\mathrm{SiO}_{2}}\right)$ of the hydrophilic $\mathrm{SiO}_{2}$ region were tested in the range of $500 \mathrm{~nm}$ and $2 \mu \mathrm{m}$. Here, the top panel shows SEM images of the patterned surfaces prior to the deposition and the lower phasemode AFM images after the deposition. As can be seen from the lower panel of Fig. 2a, highly oriented bundles were formed along the strips when the width is relatively lower at $500 \mathrm{~nm}$. As the width increases up to $2 \mu \mathrm{m}$, the nanotube bundles start to orient randomly along and across the strip direction, with the degree of alignment decreasing with the increase of the hydrophilic region.

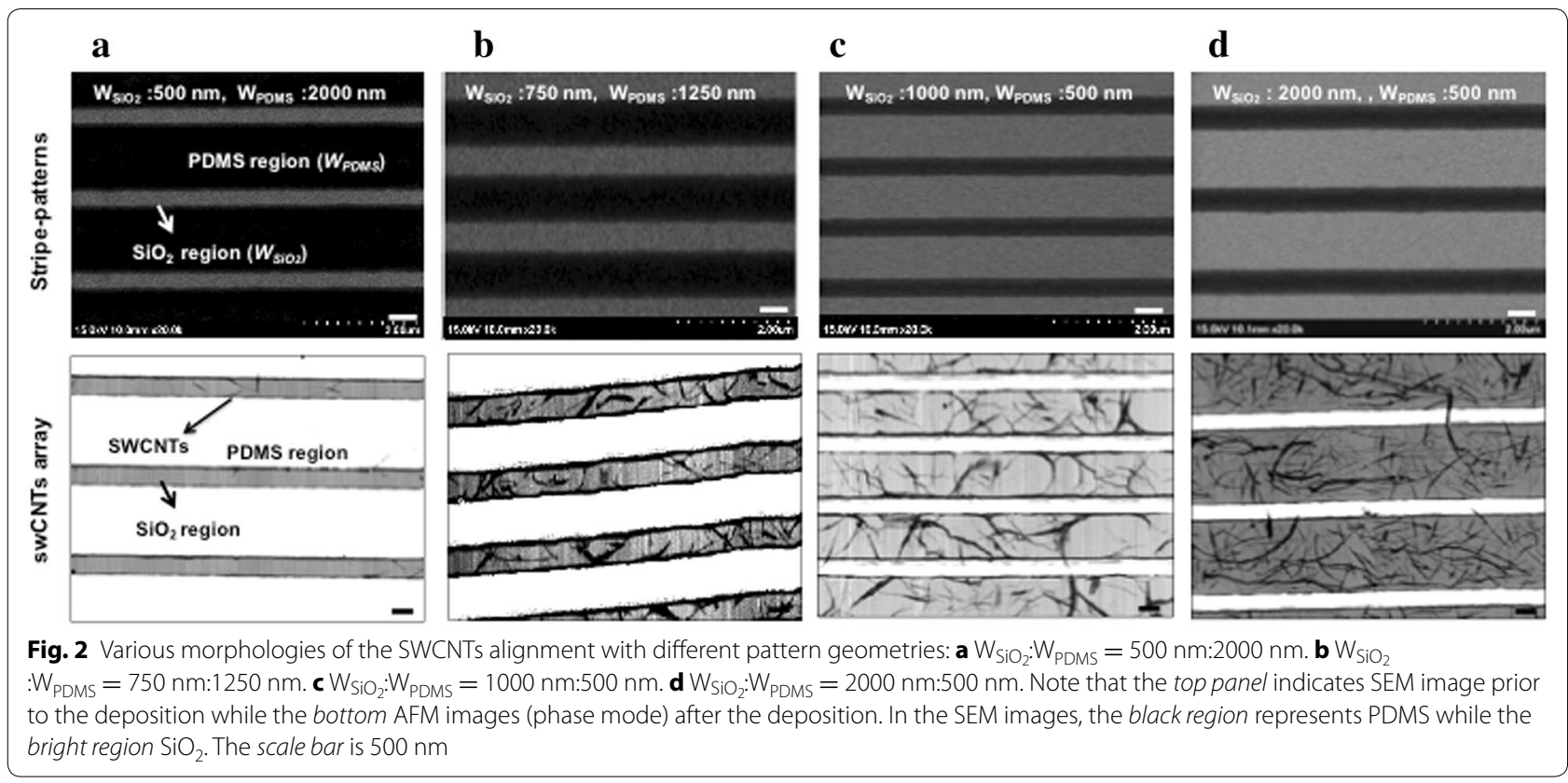


To better understand the width-dependent alignment of SWCNTs, a phase map was constructed as shown in Fig. 3. Here, the alignment tendency was classified into four representative types with varying widths of the hydrophilic region. In terms of alignment accuracy and carbon-carbon contacts, case 1 is desirable since most nanotube bundles are aligned along the strips with some interconnections between the adjacent edges (spacing $\sim 500 \mathrm{~nm}$ ). This would allow for minimum electrical path in the CNT-based electric circuits. In case 2, the nanotubes are relatively well aligned along the strips with negligible interconnections due to a relatively large spacing of $750 \mathrm{~nm}$. Interestingly, the bundles were formed frequently at one side of the edges, for which asymmetric evaporation and migration of the solution towards the pulling direction might be responsible. In cases 3 and 4 , the degree of alignment was much reduced with randomly distributed bundles of SWCNTs, which in turn increase carbon-carbon contacts. For such large widths $(>\sim 1 \mu \mathrm{m})$, it appears that directional evaporation is mitigated and thus the solution evaporates on the entire hydrophilic region before reaching the evaporation-rich edges. It is worthwhile noting that the phase map presented here is valid for the low SWCNTs concentration $(\sim 0.1 \mathrm{mg} / \mathrm{ml})$ and thus other concentrations will give different morphology and phase maps (Fig. 3).

\section{Fabrication of SWCNTs-FET device}

The current fluidic approach can be used to fabricate highly aligned CNT bundles in a simple FET device with varying source-drain separations $\left(L_{c}\right)$. Figure 4 a shows a schematic for device layout, in which the PDMS strips of $500 \mathrm{~nm}$ were fabricated onto the recessed region $(\sim 300 \mathrm{~nm}$ height) between the two gold electrodes. During the transfer process, the elastic nature of PDMS stamp allowed conformal contact even on the recessed region, resulting in uniformly patterned strips over 4 in. wafer scale. Figure $5 \mathrm{~b}$ demonstrates a large-area assembly of SWCNTs onto the pre-patterned electrode arrays. The inset image indicates that the nanotube bundles are well-oriented along the

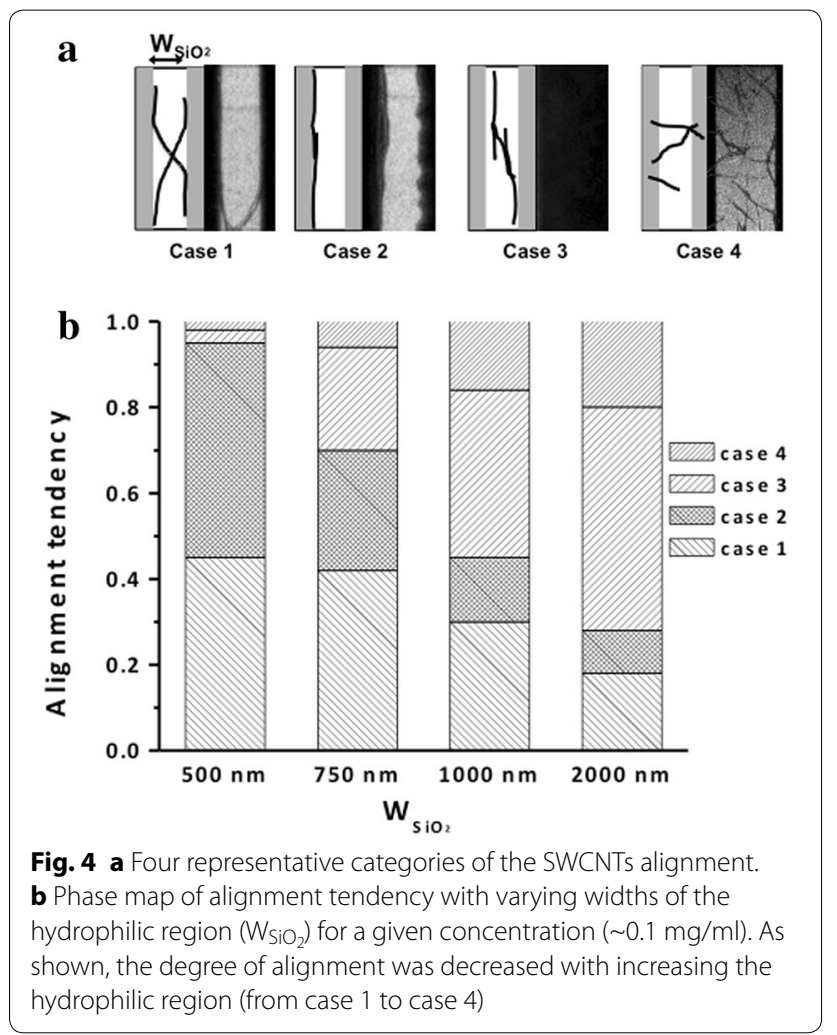

strips with some interconnections, corresponding to the case 1 in Fig. 4. Figure 5c, d shows current/voltage (I-V) characteristics of the fabricated devices, with the inset showing representative images of the SWCNTs alignment. For wider strips $\left(\mathrm{W}_{\mathrm{PDMS}}: \mathrm{W}_{\mathrm{SiO}_{2}}=1: 4\right)$ with $L_{\mathrm{c}}=4 \mu \mathrm{m}$, the distribution of the bundles is random and less-oriented, which gave rise to a higher electrical resistance $R$ of $0.216 \mathrm{M} \Omega\left(@ 25{ }^{\circ} \mathrm{C}, 0.5 \mathrm{~V}\right.$ ), which was $~ 8.6$ times higher than that with narrower strips $\left(\mathrm{W}_{\mathrm{PDMS}}: \mathrm{W}_{\mathrm{SiO}_{2}}=4: 1\right)$ $(0.025 \mathrm{M} \Omega)$. This difference is attributed to the increased carbon-carbon contacts for the random network [34]. It is noted in this regard that if all the electrical paths contain, at least, one semiconducting one, they behave like
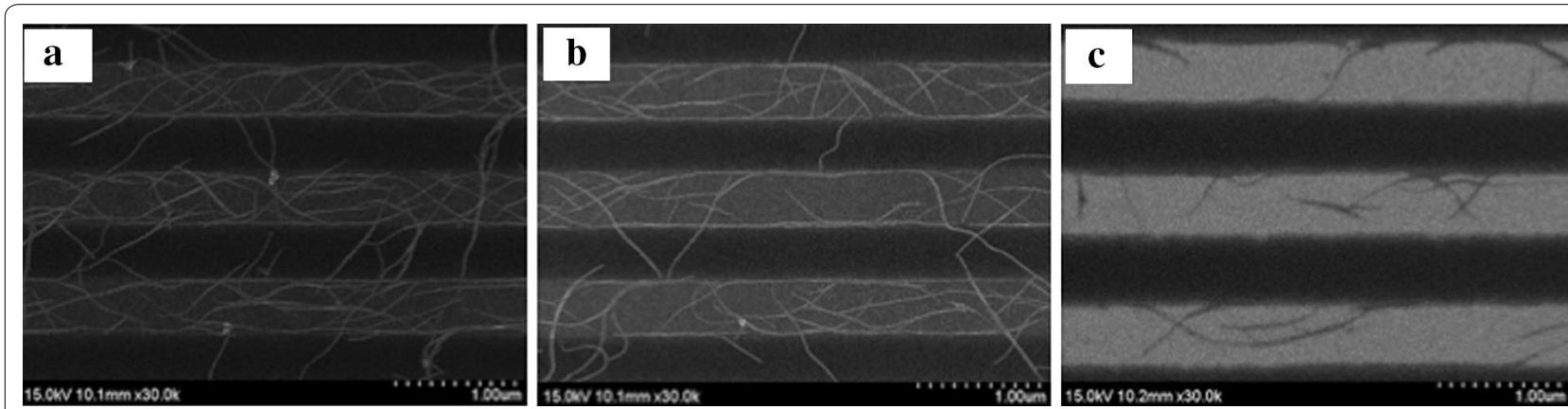

Fig. 3 Effect of the solution concentration on SWCNTs alignment: a $1 \mathrm{mg} / \mathrm{ml}, \mathbf{b} 0.5 \mathrm{mg} / \mathrm{ml}$ and $\mathbf{c} 0.1 \mathrm{mg} / \mathrm{ml}$ 


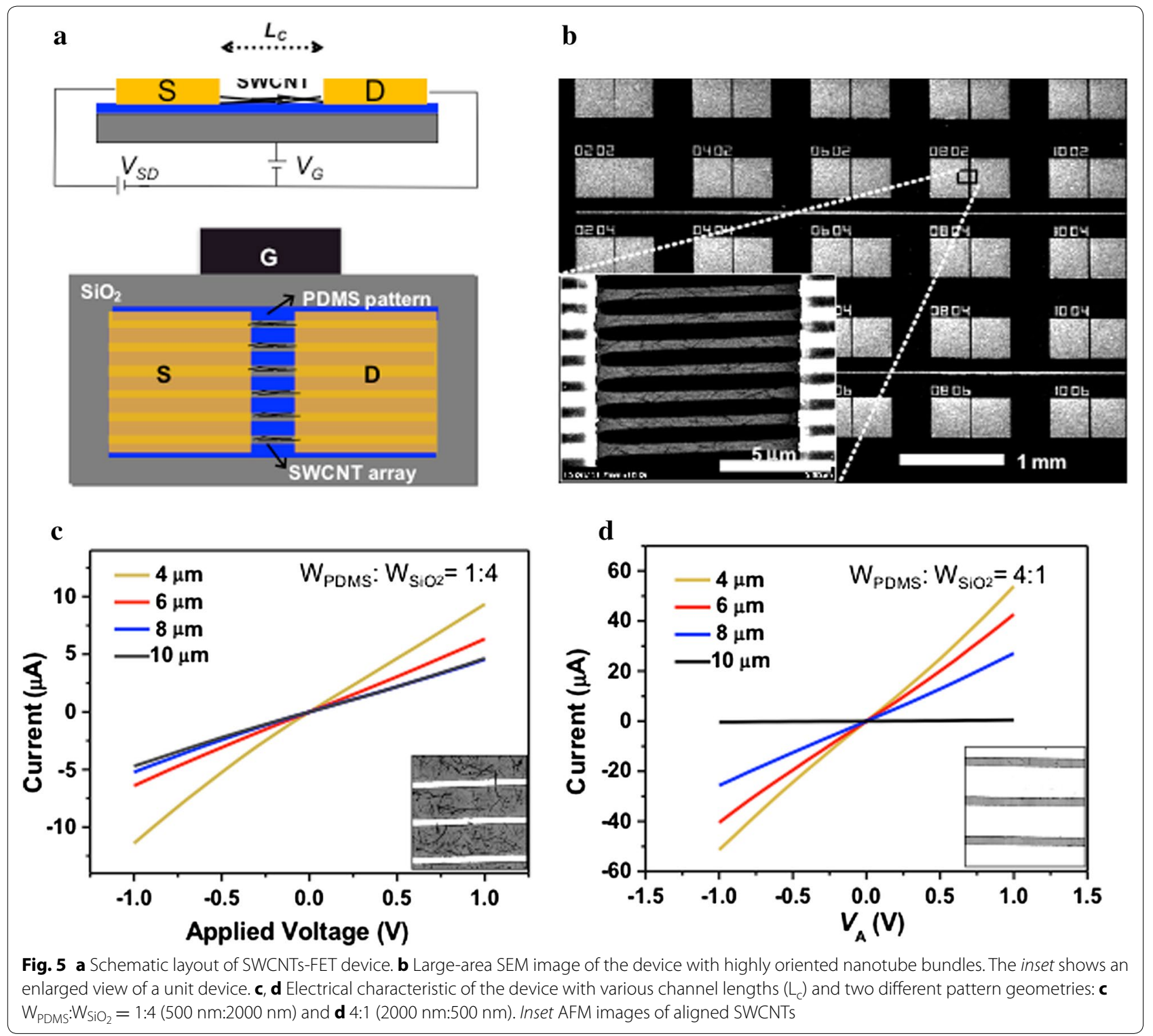

a semiconductor in the parallel-aligned SWCNTs-FET device. In contrast, the metallic conducting path is generally formed in a random network [35].

We further investigated a gating effect of highlyaligned SWCNTs devices. For a particular geometry $\left(L_{\mathrm{c}}=10 \mu \mathrm{m}, \mathrm{W}_{\mathrm{PDMS}}: \mathrm{W}_{\mathrm{SiO}_{2}}=4: 1\right)$, we observed the onstate current of $\sim 0.3 \mu \mathrm{A}$ at a drain bias $\left(V_{\mathrm{DS}}\right)$ of $-0.1 \mathrm{~V}$ (Fig. 6a). The peak transconductance $\left(\mathrm{g}_{\mathrm{m}}, \mathrm{d} I_{D} / \mathrm{d} V_{G S}\right)$ was $\sim 0.99 \mathrm{n} S$ at a drain bias of $-0.1 \mathrm{~V}$ and gate bias of $-1.5 \mathrm{~V}$. Thus, the FET device with highly-oriented CNT bundles exhibited high performance with a large turn off ratio $\left(\sim 10^{2}\right)$, compared with the same device with random network of SWCNTs with the turn off ratio being less than $\sim 10$ (Fig. 6b). The out-put signal was ensemble-averaged over six randomly located devices (each device measured three times with $\sim 134$ strips/electrode, in total 18 measurements for single output) with small device-to-device variations (deviations $\pm 3 \%$ ), suggesting that the fluidic assembly presented here is highly effective and scalable for device fabrication.

\section{Conclusion}

In this paper, we have presented a simple yet widely applicable fluidic assembly method by utilizing dip coating and directional evaporation. The topographically patterned surface in the form of alternating hydrophobic PDMS strips on the hydrophilic $\mathrm{SiO}_{2}$ substrate was used to provide a precise control over selective wetting and drying along the strip direction, completing the deposition of highly aligned bundles of SWCNTs. The method 

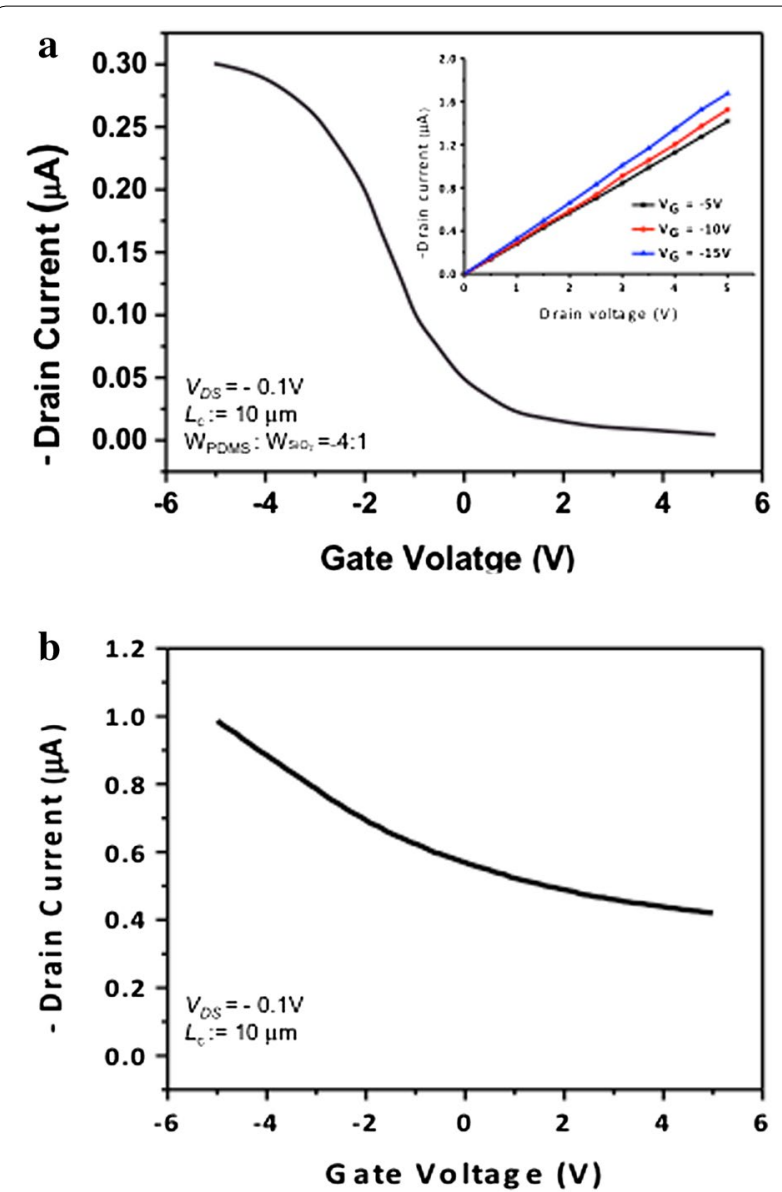

Fig. 6 A typical gating effect of the devices with $\mathbf{a}$ highly oriented

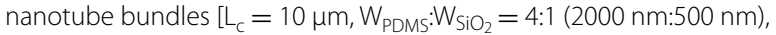
VDS $=-0.1 \mathrm{~V}]$. The inset shows output characteristics of the device, for three gate voltages $(\mathrm{VG}=-5,-10$, and $-15 \mathrm{~V})$, measured in steps of $0.5 \mathrm{~V}$. b FET device with Lc of $10 \mu \mathrm{m}$, based on SWCNT membrane (VDS: $-0.1 \mathrm{~V}$ ). The device exhibits a turn-off ratio less than $\sim 10$

involves a low-expertise and scalable dip coating process and does not require additional surface modification or external stimulus. Furthermore, the simple FET device with aligned nanotube bundles demonstrated significantly higher current density and high turn-off ratio ( $\mathrm{T} / \mathrm{O}$ ratio $\sim 100)$ as compared to that with randomly distributed bundles ( $\mathrm{T} / \mathrm{O}$ ratio $\sim<10)$. The same approach could be applied to obtain highly oriented nanomaterial arrays including nanowires or nanoparticles.

\section{Authors' contributions}

PK and TJK conducted the experiments, and analysed the results. Both authors finalized the drafted manuscript. All authors read and approved the final manuscript.

\section{Author details}

${ }^{1}$ Department of Bio and Brain Engineering, KAIST, Daejeon 34141, South Korea. ${ }^{2}$ Department of Mechanical Engineering, Inha University, Incheon 22212, South Korea.

\section{Competing interests}

The authors declare that they have no competing interests.

\section{Funding}

This research was supported from the National Research Foundation of Korea (NRF) (Grants NRF-2015H1A2A1030560 and NRF-2014M3C1B2048201). This work was also supported by INHA university Research Grant (INHA-54472).

Received: 7 December 2016 Accepted: 15 March 2017

Published online: 20 March 2017

\section{References}

1. Heo K, Cho E, Yang JE, Kim MH, Lee M, Lee BY, Kwon SG, Lee MS, Jo MH, Choi HJ, Hyeon T, Hong S (2008) Large-scale assembly of silicon nanowire network-based devices using conventional microfabrication facilities. Nano Lett 8(12):4523-4527

2. Cheng WL, Park NY, Walter MT, Hartman MR, Luo D (2008) Nanopatterning self-assembled nanoparticle superlattices by moulding microdroplets. Nat Nanotechnol 3(11):682-690

3. Shipway AN, Katz E, Willner I (2000) Nanoparticle arrays on surfaces for electronic, optical, and sensor applications. Chem Phys Chem 1(1):18-52

4. Law M, Goldberger J, Yang PD (2004) Semiconductor nanowires and nanotubes. Annu Rev Mater Res 34:83-122

5. Avouris $\mathrm{P}$, Chen ZH, Perebeinos V (2007) Carbon-based electronics. Nat Nanotechnol 2(10):605-615

6. Cao Q, Xia MG, Kocabas C, Shim M, Rogers JA, Rotkin SV (2007) Gate capacitance coupling of singled-walled carbon nanotube thin-film transistors. Appl Phys Lett 90(2):023516

7. Engel M, Small JP, Steiner M, Freitag M, Green AA, Hersam MC, Avouris P (2008) Thin film nanotube transistors based on self-assembled, aligned semiconducting carbon nanotube arrays. ACS Nano 2(12):2445-2452

8. Ishikawa FN, Chang HK, Ryu K, Chen PC, Badmaev A, De Arco LG, Shen GZ, Zhou CW (2009) Transparent electronics based on transfer printed aligned carbon nanotubes on rigid and flexible substrates. ACS Nano 3(1):73-79

9. Sekitani T, Nakajima H, Maeda H, Fukushima T, Aida T, Hata K, Someya T (2009) Stretchable active-matrix organic light-emitting diode display using printable elastic conductors. Nat Mater 8(6):494-499

10. Xu GH, Zhang Q, Huang JQ, Zhao MQ, Zhou WP, Wei F (2010) A two-step shearing strategy to disperse long carbon nanotubes from vertically aligned multiwalled carbon nanotube arrays for transparent conductive films. Langmuir 26(4):2798-2804

11. Duchamp M, Lee K, Dwir B, Seo JW, Kapon E, Forro L, Magrez A (2010) Controlled positioning of carbon nanotubes by dielectrophoresis: insights into the solvent and substrate role. ACS Nano 4(1):279-284

12. Huang JX, Fan R, Connor S, Yang PD (2007) One-step patterning of aligned nanowire arrays by programmed dip coating. Angew Chem Int Ed 46(14):2414-2417

13. Meitl MA, Zhou YX, Gaur A, Jeon S, Usrey ML, Strano MS, Rogers JA (2004) Solution casting and transfer printing single-walled carbon nanotube films. Nano Lett 4(9):1643-1647

14. Park JU, Meitl MA, Hur SH, Usrey ML, Strano MS, Kenis PJA, Rogers JA (2006) In situ deposition and patterning of single-walled carbon nanotubes by Laminar flow and controlled flocculation in microfluidic channels. Angew Chem Int Ed 45(4):581-585

15. Kim P, Baik S, Suh KY (2008) Capillarity-driven fluidic alignment of singlewalled carbon nanotubes in reversibly bonded nanochannels. Small 4(1):92-95

16. Kong J, Soh HT, Cassell AM, Quate CF, Dai HJ (1998) Synthesis of individual single-walled carbon nanotubes on patterned silicon wafers. Nature 395(6705):878-881

17. Bennett RD, Hart AJ, Miller AC, Hammond PT, Irvine DJ, Cohen RE (2006) Creating patterned carbon nanotube catalysts through the microcontact printing of block copolymer micellar thin films. Langmuir 22(20):8273-8276

18. Cao Q, Hur SH, Zhu ZT, Sun YG, Wang CJ, Meitl MA, Shim M, Rogers JA (2006) Highly bendable, transparent thin-film transistors that use 
carbon-nanotube-based conductors and semiconductors with elastomeric dielectrics. Adv Mater 18(3):304-309

19. Kocabas C, Shim M, Rogers JA (2006) Spatially selective guided growth of high-coverage arrays and random networks of single-walled carbon nanotubes and their integration into electronic devices. J Am Chem Soc 128(14):4540-4541

20. Im J, Lee IH, Lee BY, Kim B, Park J, Yu W, Kim UJ, Lee YH, Seong MJ, Lee EH, Min YS, Hong S (2009) Direct printing of aligned carbon nanotube patterns for high-performance thin film devices. Appl Phys Lett 94(5):053109

21. Liu HP, Takagi D, Chiashi S, Homma Y (2010) Transfer and alignment of random single-walled carbon nanotube films by contact printing. ACS Nano 4(2):933-938

22. Wang CJ, Cao Q, Ozel T, Gaur A, Rogers JA, Shim M (2005) Electronically selective chemical functionalization of carbon nanotubes: correlation between Raman spectral and electrical responses. J Am Chem Soc 127(32):11460-11468

23. Rao SG, Huang L, Setyawan W, Hong SH (2003) Large-scale assembly of carbon nanotubes. Nature 425(6953):36-37

24. Zheng M, Jagota A, Semke ED, Diner BA, Mclean RS, Lustig SR, Richardson RE, Tassi NG (2003) DNA-assisted dispersion and separation of carbon nanotubes. Nat Mater 2(5):338-342

25. Banerjee S, Hemraj-Benny T, Wong SS (2005) Covalent surface chemistry of single-walled carbon nanotubes. Adv Mater 17(1):17-29

26. Tasis D, Tagmatarchis N, Bianco A, Prato M (2006) Chemistry of carbon nanotubes. Chem Rev 106(3):1105-1136

27. Kim P, Kwak R, Lee SH, Suh KY (2010) Solvent-assisted decal transfer lithography by oxygen plasma bonding and anisotropic swelling. Adv Mater 22(22):2426-2429
28. Xia YN, Mrksich M, Kim E, Whitesides GM (1995) Microcontact printing of octadecylsiloxane on the surface of silicon dioxide and its application in microfabrication. J Am Chem Soc 117(37):9576-9577

29. Suh KY (2006) Surface-tension-driven patterning: combining tailored physical self-organization with microfabrication methods. Small 2(7):832-834

30. Vyawahare S, Craig KM, Scherer A (2006) Patterning lines by capillary flows. Nano Lett 6(2):271-276

31. Deegan RD, Bakajin O, Dupont TF, Huber G, Nagel SR, Witten TA (1997) Capillary flow as the cause of ring stains from dried liquid drops. Nature 389(6653):827-829

32. Sharma R, Lee CY, Choi JH, Chen K, Strano MS (2007) Nanometer positioning, parallel alignment, and placement of single anisotropic nanoparticles using hydrodynamic forces in cylindrical droplets. Nano Lett 7(9):2693-2700

33. Bigioni TP, Lin XM, Nguyen TT, Corwin El, Witten TA, Jaeger HM (2006) Kinetically driven self assembly of highly ordered nanoparticle monolayers. Nat Mater 5(4):265-270

34. Stadermann M, Papadakis SJ, Falvo MR, Novak J, Snow E, Fu Q, Liu J, Fridman Y, Boland JJ, Superfine R, Washburn S (2004) Nanoscale study of conduction through carbon nanotube networks. Phys Rev B 69(20):201402

35. Lee M, Noah M, Park J, Seong MJ, Kwon YK, Hong S (2009) "Textured" network devices: overcoming fundamental limitations of nanotube/ nanowire network-based devices. Small 5(14):1642-1648

\section{Submit your manuscript to a SpringerOpen ${ }^{\circ}$ journal and benefit from:}

- Convenient online submission

- Rigorous peer review

- Immediate publication on acceptance

- Open access: articles freely available online

- High visibility within the field

- Retaining the copyright to your article

Submit your next manuscript at $\boldsymbol{\nabla}$ springeropen.com 